\title{
Challenges in sodium intake reduction and meal consumption patterns among participants with metabolic syndrome in a dietary trial
}

Jinsong Wang ${ }^{1,2}$, Barbara C Olendzki ${ }^{2}$, Nicole M Wedick ${ }^{2}$, Gioia M Persuitte ${ }^{3}$, Annie L Culver ${ }^{2}$, Wenjun Li ${ }^{2}$, Philip A Merriam², James Carmody², Hua Fang ${ }^{4}$, Zhiying Zhang ${ }^{2}$, Gin-Fei Olendzki ${ }^{2}$, Liang Zheng ${ }^{2,5}$ and Yunsheng $\mathrm{Ma}^{2^{*}}$

\begin{abstract}
Background: Dietary guidelines suggest limiting daily sodium intake to $<2,300 \mathrm{mg}$ for the general population, and $<1,500 \mathrm{mg} / \mathrm{d}$ for those with certain cardiovascular risk factors. Despite these recommendations, few Americans are able to achieve this goal. Identifying challenges in meeting these guidelines is integral for successful compliance. This analysis examined patterns and amount of daily sodium intake among participants with metabolic syndrome enrolled in a one-year dietary intervention study.

Methods: Two hundred forty participants with metabolic syndrome enrolled in a dietary intervention trial to lose weight and improve dietary quality. Three 24-hour dietary recalls were collected at each visit which provided meal patterns and nutrient data, including sodium intake. A secondary data analysis was conducted to examine sodium consumption patterns at baseline and at one-year study visits. Sodium consumption patterns over time were examined using linear mixed models.

Results: The percentage of meals reported eaten in the home at both baseline and one-year follow-up was approximately $69 \%$. Follow-up for the one-year dietary intervention revealed that the participants who consumed sodium greater than 2,300 mg/d declined from $75 \%$ (at baseline) to $59 \%$, and those that consumed higher than $1,500 \mathrm{mg} / \mathrm{d}$ declined from $96 \%$ (at baseline) to $85 \%$. Average sodium intake decreased from 2,994 $\mathrm{mg}$ at baseline to $2,558 \mathrm{mg}$ at one-year $(P<0.001)$, and the sodium potassium ratio also decreased from 1.211 to $1.047(P<0.001)$. Sodium intake per meal varied significantly by meal type, location, and weekday, with higher intake at dinner, in restaurants, and on weekends. At-home lunch and dinner sodium intake decreased $(P<0.05)$, while dinner sodium intake at restaurant/fast food chains increased from baseline to one-year $(P<0.05)$.

Conclusion: Sodium intake for the majority of participants exceeded the recommended dietary guidelines. Findings support actions that encourage low-sodium food preparation at home and encourage public health policies that decrease sodium in restaurants and prepared foods.
\end{abstract}

Keywords: Sodium, Diet, Metabolic syndrome, Meal type, Meal location

\footnotetext{
* Correspondence: Yunsheng.Ma@umassmed.edu

${ }^{2}$ Division of Preventive and Behavioral Medicine, Department of Medicine,

University of Massachusetts Medical School, Worcester, MA, USA

Full list of author information is available at the end of the article
} 


\section{Introduction}

High sodium intake is associated with many chronic diseases such as stroke and cardiovascular disease (CVD) [1-6]. It has been estimated that reducing sodium intake to $<2300 \mathrm{mg} / \mathrm{d}$ may eliminate 11 million hypertension cases, save 18 billion health care dollars, and ultimately gain 312,000 quality-adjusted life years in the United States (U.S.) [7].

Dietary Guidelines for Americans (DGA) 2010 suggest a reduction in daily sodium intake to less than $2300 \mathrm{mg}$ and even further reduction to $1500 \mathrm{mg}$ for those 51 years and older, African-American, or individuals with hypertension, diabetes, or chronic kidney disease [8]. Despite these recommendations, sodium intake remains high in the U.S. with an average daily consumption of 3,266 mg for individuals 2 years of age and older [9].

Metabolic syndrome (MetS), characterized by central obesity, hypertension, dyslipidemia, and insulin resistance, is strongly associated with risk for type 2 diabetes and CVD $[10,11]$. The prevalence of metabolic syndrome in the U.S. increased from $27.9 \%$ in 1999 to $34.1 \%$ in 2006 [11-13]. Many studies indicate that high sodium intake is associated with MetS risk [14-17]; however, relationships between sodium intake and meal consumption patterns among MetS patients remain unclear. Therefore, to evaluate characteristics associated with sodium intake and variations in sodium intake patterns (by different locations and days of the week) we used data from our dietary intervention trial at baseline and at the end of the one-year intervention. We hypothesized an improvement in sodium intake patterns over our one-year dietary intervention.

\section{Methods}

\section{Study sample}

Details of the "Can Do" study methodology have been described elsewhere [18]. Briefly, recruitment was conducted at the University of Massachusetts Medical School (UMMS), Worcester, MA in May 2009 and was completed in February 2013. Study recruitment fliers were posted at the UMMS, local public libraries and churches; announcements were uploaded onto UMMS intranet; and recruitment advertisements were posted in local newspapers and on Craigslist. Institutional Review Board at UMMS approved this study. Eligibility criteria included the following: 1) Met diagnostic criteria for the MetS [19]; in brief, waist circumference $>102 \mathrm{~cm}$ for men and $88 \mathrm{~cm}$ for women, triglycerides levels $\geq 150 \mathrm{mg} / \mathrm{dL}$, high-density lipoprotein cholesterol (HDL-C) levels $<40 \mathrm{mg} /$ $\mathrm{dL}$ for men and $<50 \mathrm{mg} / \mathrm{dL}$ for women, hypertension with systolic blood pressure $\geq 130 \mathrm{mmHg}$ and diastolic blood pressure $\geq 85 \mathrm{mmHg}$, and fasting glucose concentrations $\geq$ $110 \mathrm{mg} / \mathrm{dL}$; 2) Interest in losing weight and with body mass index (BMI) $30-40 \mathrm{~kg} / \mathrm{m}^{2}$; 3) 20-70 y; 4) Telephone in the home or easy access to one; 5) Able to respond informed consent; 6) with physician's approval to participate; 7) non-smoker (given nicotine's weight and HDL-C suppression effect, and smoking cessation's weight gain effect); and 8) speak, read and write English fluently. Individuals were excluded if they: 1) Had clinically diagnosed diabetes, or a fasting blood glucose levels $\geq 126 \mathrm{mg} / \mathrm{dl}$ at screening; 2) Had an acute coronary event within the 6 months prior to study; 3 ) Were pregnant or lactating; 4) Had polycystic ovary syndrome; 5) Planned to move out of the area within the 12-month study period; 6) Had a diagnosis of a medical condition that would preclude adherence to study dietary recommendations (e.g., inflammatory bowel disease, active diverticulitis, renal disease); 7) Had elevated depression [Center for Epidemiologic Studies Depression score $>=21$ ] or suicidal ideation; 8) Were following a low-carbohydrate, high-fat dietary regimen such as the Atkins Diet; 9) Were participating in any current weight loss program; 10) Had bariatric surgery or was currently using weight loss education; or, 11) Had been diagnosed with an eating disorder (bulimia nervosa or binge eating). For the total of 1777 screened subjects, 1537 were excluded due to various reasons, i.e. telephone screening ineligible, screening visit ineligible, refused screening and/or baseline, and baseline visit ineligible.

A total of 240 obese subjects were randomized into one of the two conditions: 1) a high fiber diet (HF) or; 2) the American Heart Association (AHA) diet (control). Subjects following the HF diet received instructions toward achieving the goal of taking $30 \mathrm{~g}$ or more fiber daily from various foods; while those in the control group followed the AHA 2006 guidelines [20]. Briefly, based on a 2000 calories daily level, people should achieve $50-55 \%$ of calories from carbohydrate, $15-20 \%$ from protein, and 30-35\% calories from fat. Specifically, people should 1) balance food intake and physical activity for a healthy weight; 2) consume at least 4.5 cups of fruit and vegetables; 3 ) consume at least two 3.5 ounces fish especially oily fish a week; 4) consume at least $50 \%$ grain intake as high fiber, whole-grain foods; 5 ) reduce sodium intake to less than $1500 \mathrm{mg} / \mathrm{d}$; 6) minimize added sugar intake in foods and beverages and minimize hydrogenated fats content; 7) at least 4 servings of nuts, legumes, and seeds per week; 8) limited to no more than 2 servings of processed meats per week; 9) reduce saturated fat less than $7 \%$ of total energy intake, trans-fat to less than $1 \%$ of energy, and cholesterol to less than $300 \mathrm{mg} / \mathrm{d}$ by choosing lean foods vegetable alternative; 10) choose fat-free or low-fat ( $1 \%$ fat) dairy products; 11) choose moderate to no alcohol intake.

\section{Dietary assessment}

To assess subjects' dietary intake, three 24-hour dietary recalls (two week days and one weekend) were completed by study dietitians using the Nutritional Data System for 
Research (NDS-R, 2010-2012, Minneapolis, MN) at both baseline and one-year visits [21]. All participants received a food portion visual booklet prior to receiving the assessment calls to facilitate portion size estimation. Meal types were identified by participants as: breakfast, lunch, dinner or snack. Meal locations (where food was consumed) were chosen from selected options in NDS-R and grouped as follows: "At home" indicates meals eaten at home; "Away from home" includes eating meals at work, school, day care, friend's home, community meal program, party, reception, sporting event, and other; and "Restaurant/fast food" includes eating meals at a restaurant, cafeteria, fast food chains, deli, take-out, or store. The 24-hour dietary recall provided variation of sodium intake by meal type, location, and day of the week. Sodium density was defined as sodium consumption per kilocalorie (kcal) of intake. Subjects were invited to complete a dietary attitudes questionnaire at both baseline and at one-year visit to query the importance of eating foods low in sodium.

\section{Sample size consideration}

Sample size calculation was based on the method developed by Frison and Pocock using STATA SE 10 (STATA, College Station, TX) [22]. Parameters used for sample size calculation were on the basis of our pilot trial and documented data from the metabolic patients in our clinics. We recruited 190 subjects (95 per group) to have $80 \%$ power at $5 \%$ significance level; to account for a potential attrition rate of $20 \%$, we finalized a total of 240 subjects.

\section{Statistical analysis}

Chi-squared test were performed for categorical variables. Continuous variables were presented as means \pm standard error (S.E.). Sodium intake and sodium density were evaluated using linear mixed models, which were used to examine the differences between baseline and one-year visits, meal location, meal type, and meal time (weekdays versus weekends). Four models were fitted in the analyses of meal location and day of week. In Model 1, independent variables included time-points, meal type, location, gender, study condition, the day of week, and the interaction of time-points, meal type and the day of week. In Model 2 when sodium intake was fitted as dependent variable, meal location was removed to test the difference between weekdays and weekend days. Model 3 and Model 4 adjusted the caloric intake based on Model 1 and Model 2 , respectively. Differences were considered significant at $p<0.05$. Statistical analyses were performed using SAS 9.2 software (SAS Institute, Cary, North Carolina).

\section{Results}

Two hundred and forty obese subjects participated in the present study [mean and standard deviation (SD): BMI: $35 \pm 3 \mathrm{~kg} / \mathrm{m}^{2}$ ] and met at least three components of MetS. The average age was $52(\mathrm{SD}=10)$ years old and $72 \%$ were women. Figure 1 shows the improvement of sodium intake at baseline and one-year visits among participants at the 1500 and $2300 \mathrm{mg} / \mathrm{d}$ limits recommended by the DGA and the AHA, respectively $[8,20,23]$. The percentage of excess sodium intake decreased $(p<0.001)$ at each cut-point.

Sodium intake stratified by selected demographic characteristics is presented in Table 1 . The average sodium intake decreased from $2994 \pm 72 \mathrm{mg} / \mathrm{d}$ at baseline to $2558 \pm$ $77 \mathrm{mg} / \mathrm{d}$ at one-year visit $(p<0.001)$; the sodium potassium ratio also decreased from $1.211 \pm 0.027$ to $1.047 \pm 0.031$. At baseline, sodium consumption was significantly higher among subjects who were younger than $51 \mathrm{y}$, male, and employed $(p<0.001 ; p=0.014 ; p=0.004$, respectively). At the one-year visit, sodium intake was consistently reduced; however a significant difference was only observed between males $(3051 \pm 146 \mathrm{mg} / \mathrm{d})$ and females $(2380 \pm 88 \mathrm{mg} / \mathrm{d} ; \mathrm{p}<0.001$ Table 1 also shows that there were no statistically significant differences between the AHA and high fiber diet groups for daily sodium intake or sodium density at both baseline and at one year.

In addition, dietary attitudes might also play a role in decisions regarding sodium consumption. At baseline, the 44 participants (18.4\%) who were ambivalent or disagreed that limiting sodium is important had a higher sodium intake (3322 $\pm 155 \mathrm{mg} / \mathrm{d}$ ) compared to those who ranked sodium intake as important $(2914 \pm 76 \mathrm{mg} / \mathrm{d}$; $\mathrm{p}=0.017)$. One-year after the intervention, sodium intake was consistently reduced regardless of whether subjects agreed with this concept.

To increase statistical power, we used pooled data for further analyses. Sodium consumption (mg) and sodium

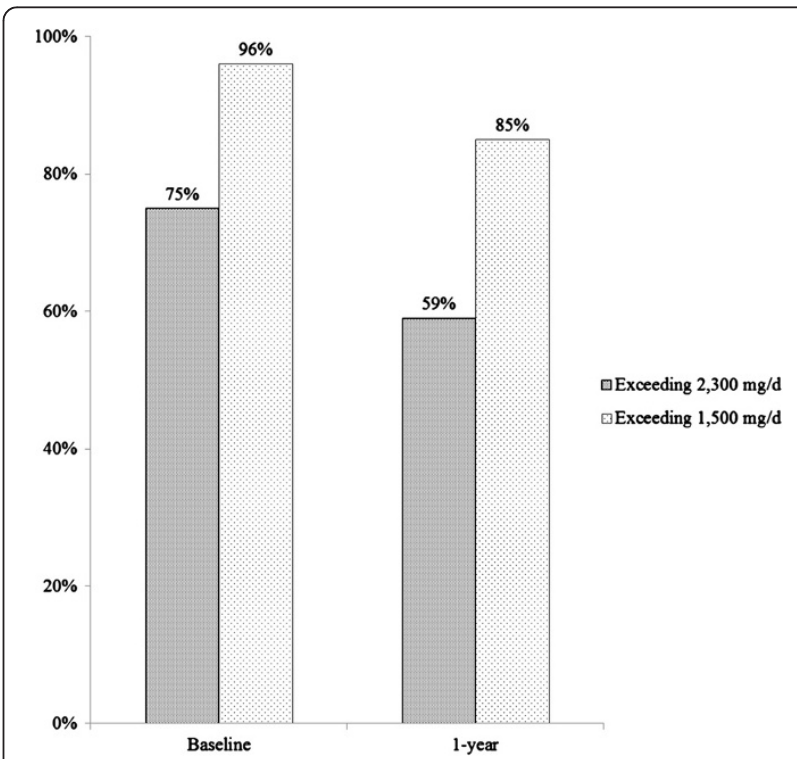

Figure 1 The percentage of excess sodium intake over time points. 
Table 1 Sodium intake by participants' characteristics ${ }^{1}$

\begin{tabular}{|c|c|c|c|c|c|}
\hline \multirow[t]{2}{*}{ Variable } & \multicolumn{2}{|c|}{ Baseline } & \multicolumn{2}{|c|}{ One year } & \multirow{2}{*}{$\begin{array}{c}P \text { for } \\
\text { time-points }\end{array}$} \\
\hline & $\mathrm{n}$ & $\begin{array}{c}\text { Mean (S.E.) } \\
\text { (mg/day) }\end{array}$ & $\mathrm{n}$ & $\begin{array}{c}\text { Mean (S.E.) } \\
\text { (mg/day) }\end{array}$ & \\
\hline Sodium intake (mg/day) & 240 & $2994(72)$ & 184 & $2558(77)$ & $<0.001$ \\
\hline Sodium density (mg/kcal) & 240 & $1.613(0.025)$ & 184 & $1.660(0.034)$ & 0.249 \\
\hline Sodium/potassium ratio & 240 & $1.211(0.027)$ & 184 & $1.047(0.031)$ & $<0.001$ \\
\hline \multicolumn{6}{|l|}{ Treatment arms } \\
\hline AHA diet & 119 & $3063(99)$ & 92 & $2415(110)$ & \multirow[t]{3}{*}{$<0.001$} \\
\hline High fiber diet & 121 & 2927 (98) & 92 & $2694(110)$ & \\
\hline$p$ value $e^{3}$ & & 0.330 & & 0.074 & \\
\hline \multicolumn{6}{|l|}{ Gender } \\
\hline Female & 173 & $2742(77)$ & 135 & $2380(88)$ & \multirow[t]{3}{*}{$<0.001$} \\
\hline Male & 67 & $3645(125)$ & 49 & $3051(146)$ & \\
\hline$p$ value $^{3}$ & & $<0.001$ & & $<0.001$ & \\
\hline \multicolumn{6}{|l|}{ Age group } \\
\hline$<51$ y & 93 & $3211(112)$ & 59 & $2546(140)$ & \multirow[t]{3}{*}{$<0.001$} \\
\hline$\geq 51 \mathrm{y}$ & 147 & $2857(89)$ & 125 & $2564(96)$ & \\
\hline$p$ value ${ }^{3}$ & & 0.014 & & 0.916 & \\
\hline \multicolumn{6}{|l|}{ Race/ethnicity } \\
\hline Caucasian & 213 & $3034(74)$ & 165 & $2545(84)$ & \multirow[t]{3}{*}{0.145} \\
\hline Others & 27 & $2683(208)$ & 19 & $2670(248)$ & \\
\hline$p$ value $^{3}$ & & 0.115 & & 0.634 & \\
\hline \multicolumn{6}{|l|}{ Education } \\
\hline High school diploma or less & 33 & 2989 (189) & 25 & $2843(217)$ & \multirow[t]{4}{*}{0.005} \\
\hline Bachelor's degree or less & 146 & $3054(90)$ & 108 & $2561(104)$ & \\
\hline Graduate/professional & 59 & $2833(141)$ & 49 & $2398(155)$ & \\
\hline$p$ value ${ }^{3}$ & & 0.509 & & 0.095 & \\
\hline \multicolumn{6}{|l|}{ Household income } \\
\hline$\$ 0-\$ 30000$ & 24 & $3104(220)$ & 15 & $2617(270)$ & \multirow[t]{6}{*}{$<0.001$} \\
\hline$\$ 30000-\$ 50000$ & 43 & $3167(165)$ & 36 & $2567(180)$ & \\
\hline$\$ 50000-\$ 75000$ & 40 & $2851(171)$ & 33 & $2345(188)$ & \\
\hline More than $\$ 75000$ & 79 & $3167(122)$ & 60 & $2612(139)$ & \\
\hline Unclear & 54 & $2662(147)$ & 40 & $2625(171)$ & \\
\hline$p$ value ${ }^{3}$ & & 0.096 & & 0.419 & \\
\hline \multicolumn{6}{|l|}{ Currently working } \\
\hline Full-time or part-time & 188 & $3101(78)$ & 145 & $2550(89)$ & \multirow[t]{3}{*}{0.027} \\
\hline Others & 52 & 2607 (149) & 39 & $2590(172)$ & \\
\hline$p$ value ${ }^{3}$ & & 0.004 & & 0.837 & \\
\hline \multicolumn{6}{|l|}{ Marital status } \\
\hline Married & 162 & $2979(85)$ & 121 & $2590(99)$ & \multirow[t]{3}{*}{$<0.001$} \\
\hline Not Married & 78 & $3026(123)$ & 63 & $2498(137)$ & \\
\hline$p$ value ${ }^{3}$ & & 0.753 & & 0.584 & \\
\hline \multicolumn{6}{|c|}{ Components of metabolic syndrome } \\
\hline 3 & 71 & $2820(126)$ & 52 & $2573(166)$ & \multirow[t]{2}{*}{$<0.001$} \\
\hline 4 & 96 & $3171(108)$ & 76 & $2639(126)$ & \\
\hline
\end{tabular}


Table 1 Sodium intake by participants' characteristics ${ }^{1}$ (Continued)

\begin{tabular}{lcccc}
\hline $\mathbf{5}$ & 72 & $2902(125)$ & 44 & $2446(166)$ \\
$\boldsymbol{p}$ value $^{\mathbf{3}}$ & & 0.096 & 0.796 \\
Dietary attitudes to low sodium & 195 & $2914(76)$ & 169 & $2531(82)$ \\
Agree limiting sodium is important & 44 & $3322(155)$ & 15 & $2928(258)$ \\
Not sure/disagree sodium is important & & 0.017 & 0.141 \\
$\boldsymbol{P}_{\text {value }}^{\mathbf{3}}$ & & & 0.008 \\
\hline
\end{tabular}

${ }^{1}$ Sodium intakes per meal described with mean \pm standard error and were estimated by LSMEANS of PROC MIXED model in SAS.

${ }^{2} P$ values for time-points were compared at baseline and 1-year and determined from mixed models fitting item, time-points and interaction between them However, none of the interaction terms were significant in the models.

${ }^{3} P$ values compared the differences between groups at the same time-point and were determined from LSMEANS of PROC MIXED model in SAS.

Table 2 Sodium intake ( $\mathrm{mg} / \mathrm{meal}$ ) and sodium density $(\mathrm{mg} / \mathrm{kcal})$ by meal type, weekday and location at baseline and one year ${ }^{1}$

\begin{tabular}{|c|c|c|c|c|c|c|c|c|}
\hline \multirow[b]{2}{*}{ Location $^{2,7}$} & \multicolumn{2}{|c|}{ Breakfast } & \multicolumn{2}{|c|}{ Lunch } & \multicolumn{2}{|c|}{ Dinner } & \multicolumn{2}{|c|}{ Snack } \\
\hline & Baseline & One-year & Baseline & One-year & Baseline & One-year & Baseline & One-year \\
\hline \multicolumn{9}{|l|}{ At home } \\
\hline & $n=273$ & $n=275$ & $n=184$ & $n=171$ & $n=409$ & $n=330$ & $n=695$ & $n=535$ \\
\hline Sodium intake & $487 \pm 39$ & $425 \pm 39$ & $1062 \pm 47^{4}$ & $883 \pm 49$ & $1281 \pm 33^{4}$ & $1058 \pm 36$ & $228 \pm 26$ & $215 \pm 30$ \\
\hline Sodium density & $1.29 \pm 0.05$ & $1.28 \pm 0.06$ & $2.22 \pm 0.11$ & $2.36 \pm 0.12$ & $1.94 \pm 0.06$ & $1.91 \pm 0.07$ & $1.02 \pm 0.04$ & $1.29 \pm 0.14$ \\
\hline \multicolumn{9}{|l|}{ Away from home } \\
\hline & $n=67$ & $n=59$ & $n=140$ & $n=131$ & $n=19$ & $n=18$ & $n=302$ & $n=220$ \\
\hline Sodium intake & $527 \pm 77$ & $394 \pm 82$ & $1102 \pm 54^{4}$ & $841 \pm 56$ & $1317 \pm 142$ & $1132 \pm 146$ & $169 \pm 38$ & $193 \pm 45$ \\
\hline Sodium density & $1.38 \pm 0.09$ & $1.22 \pm 0.13$ & $2.13 \pm 0.09$ & $2.04 \pm 0.12$ & $2.30 \pm 0.24$ & $2.26 \pm 0.34$ & $0.94 \pm 0.07$ & $0.95 \pm 0.08$ \\
\hline \multicolumn{9}{|c|}{ Restaurant/fast food } \\
\hline & $n=25$ & $n=15$ & $n=65$ & $n=57$ & $n=62$ & $n=59$ & $n=37$ & $n=9$ \\
\hline Sodium intake & $1023 \pm 124^{5}$ & $881 \pm 161^{5}$ & $1478 \pm 78^{5}$ & $1488 \pm 83^{5}$ & $1610 \pm 80^{4,5}$ & $1861 \pm 82^{5}$ & $274 \pm 103$ & $670 \pm 206^{5}$ \\
\hline Sodium density & $1.68 \pm 0.12^{5}$ & $1.85 \pm 0.19^{5}$ & $2.19 \pm 0.13$ & $2.29 \pm 0.13$ & $1.80 \pm 0.13$ & $2.00 \pm 0.14$ & $0.81 \pm 0.15$ & $1.36 \pm 0.40$ \\
\hline \multicolumn{9}{|l|}{ Weekdays $s^{3,7}$} \\
\hline & $n=225$ & $n=248$ & $n=249$ & $n=254$ & $n=307$ & $n=279$ & $n=680$ & $n=554$ \\
\hline Sodium intake & $488 \pm 44$ & $413 \pm 42$ & $1098 \pm 42^{4}$ & $948 \pm 41$ & $1256 \pm 38^{4}$ & $1137 \pm 40$ & $168 \pm 27$ & $200 \pm 30$ \\
\hline Sodium density & $1.32 \pm 0.05$ & $1.28 \pm 0.06$ & $2.22 \pm 0.09$ & $2.26 \pm 0.09$ & $1.91 \pm 0.07$ & $1.93 \pm 0.08$ & $0.93 \pm 0.04$ & $1.25 \pm 0.13$ \\
\hline \multicolumn{9}{|l|}{ Weekend days ${ }^{3,7}$} \\
\hline & $n=140$ & $n=101$ & $n=140$ & $n=105$ & $n=183$ & $n=128$ & $n=354$ & $n=210$ \\
\hline Sodium intake & $587 \pm 54$ & $464 \pm 64$ & $1213 \pm 54^{4}$ & $965 \pm 63$ & $1420 \pm 48^{4,6}$ & $1233 \pm 57$ & $271 \pm 36^{6}$ & $204 \pm 46$ \\
\hline Sodium density & $1.37 \pm 0.07$ & $1.33 \pm 0.10$ & $2.11 \pm 0.10$ & $2.16 \pm 0.13$ & $1.97 \pm 0.10$ & $1.96 \pm 0.11$ & $1.09 \pm 0.07$ & $1.05 \pm 0.10$ \\
\hline
\end{tabular}

${ }^{1}$ Sodium intakes per meal and sodium density per meal described with mean \pm standard error and were estimated by LSMEANS of PROC MIXED model in SAS. ${ }^{2}$ Model 1: Tested by Proc Mixed model in SAS, fitting sodium intake or sodium density as the dependent variable, independent variables included meal type $(P<0.001)$, day of week $(P<0.001)$, time-point $(P=0.238)$, location $(P<0.001)$, gender $(P<0.001)$, condition $(P=0.836)$ and interaction of meal and location and time-point $(P<0.001)$ as fixed effects, and subject ID as a random effect.

${ }^{3}$ Model 2: Tested by Proc Mixed model in SAS, fitting sodium intake or sodium density as dependent variable, independent variables included meal type $(P<0.001)$, day of week $(P<0.001)$, time-point $(P<0.001)$, gender $(P<0.001)$, condition $(P=0.802)$ and interaction of meal and weekday and time-point $(P=0.024)$ as fixed effects, and subject ID as a random effect.

${ }^{4} P<0.05$ and $P$ values compared differences between baseline and one year and were determined from LSMEANS of PROC MIXED model in SAS.

${ }^{5} P<0.05$ and $P$ values compared differences between restaurant/fast food and eaten at home at the same time-point and determined from LSMEANS of PROC MIXED model in SAS.

${ }^{6} P<0.05$ and $P$ values compared differences to weekdays and determined from LSMEANS of PROC MIXED in SAS.

${ }^{7}$ For sodium intake, Models 3 and 4 were additionally adjusted for total caloric intake and all aforementioned statistically significant differences were attenuated towards the null. 
density ( $\mathrm{mg} / \mathrm{kcal}$ ) by meal type, location, and weekday are presented in Table 2. In general, the majority of participants ate most of their meals at home with the majority of their sodium intake coming from dinner at home and when eating at restaurant/fast food chains anytime. Their sodium intake declined (except when eating at restaurant/ fast food chains) after the one-year intervention.

After the one-year intervention, subjects consumed lower amounts of sodium when they ate at home with significant differences observed at lunch $(1062 \pm 47$ versus $883 \pm 49 \mathrm{mg} ; \mathrm{p}<0.05)$ and dinner $(1281 \pm 33$ versus $1058 \pm 36 \mathrm{mg} ; \mathrm{p}<0.05)$. Sodium intake when subjects ate away from home also decreased after the one-year intervention; however, a significant difference was only observed at lunch $(1102 \pm 54$ versus $841 \pm 56 \mathrm{mg}$; $\mathrm{p}<0.05)$. Compared to baseline, sodium intake after the one-year intervention increased when subjects ate at restaurants/fast food chains with a significant difference for dinner $(1610 \pm 80$ versus $1861 \pm 82 \mathrm{mg} ; \mathrm{p}<0.05)$. However, the sodium density per meal between meal locations and the day of week were similar except for breakfast when consumed away from home or at restaurant/fast food (Baseline: $1.68 \pm 0.12$ versus $1.29 \pm 0.05 \mathrm{mg} / \mathrm{kcal}$; $\mathrm{p}<0.05$; One-year: $1.85 \pm 0.19$ versus $1.28 \pm 0.06 \mathrm{mg} / \mathrm{kcal}$; $\mathrm{p}<0.05)$.

\section{Discussion}

Previous studies have reported that over 83\% of Americans consume sodium higher than $2300 \mathrm{mg}$ per day $[8,24,25]$. Our analysis identified dietary locations and meals that may be targeted to improve the excessive sodium intake among people with metabolic syndrome. We observed that sodium intake significantly declined during our study intervention similar to the DASH diet findings $(2558 \mathrm{mg} / \mathrm{d}$ versus $2473 \mathrm{mg} / \mathrm{d}$ ) [26]; however, the decrease may be a result of reduced total energy intake since sodium density did not favorably change. Moreover, the sodium density remained similar for every location of meals consumed, even when meals eaten at home might have been be easier to manipulate.

Our one-year dietary intervention helped metabolic syndrome participants reduce sodium consumption; however their intakes remained much higher than the $1500 \mathrm{mg}$. AHA recommendation. Much like the findings from the National Health and Nutrition Examination Survey (NHANES) [9,27], our participants chose to consume processed foods including bread and rolls, cold cuts/ cured meats, pizza, poultry, soups, sandwiches, cheese, etc. (data not shown). Further, similar to other studies, our study found that mean sodium consumption was significantly greater for foods obtained from fast food or other restaurants and stores, indicating that sodium consumption mostly comes not only from table salt, but particularly salt added to processed foods $[8,9,25,28]$. Since raw/fresh foods contain much less sodium than prepared or processed foods [29], the Dietary Guidelines for Americans (2010) suggest that people eat more fresh and home-prepared foods, eat fewer processed foods, and select lower sodium items at restaurants. However, to better understand and follow these recommendations requires a very knowledgeable and motivated consumer able to identify and choose low sodium foods at restaurants. Since many foods consumed already have salt added, instructing individuals to cut back on added salt is unlikely to achieve the dietary guidelines.

Informed individual choices and population-based interventions are important approaches to reduce sodium consumption [30]. Simply recommending a reduction in sodium without support from the overall food suppliers is unlikely to achieve the desired outcomes without a significant decrease in calories, which may not be appropriate for every adult. Rather, a change in dietary sodium intake requires strong public health policies directed at the reduction of sodium in commercial processing, accompanied by lifestyle initiatives that encourage the preparation of higher quality foods using fresh ingredients without added sodium.

Policies for food and menu labeling have been proposed to improve the food environment. However, overall sodium consumption remains high in the U.S. [31]. To achieve meaningful sodium reductions and to help consumers make healthful choices, we need additional strategies that increase the availability of lower sodium products and reduce the amount of sodium in foods served outside the home, while expanding educational efforts that facilitate these healthy choices $[32,33]$.

The attention to salt reduction has been increased worldwide, with eleven countries in the European Union on board to make a $16 \%$ reduction in salt intake over the next 4 years [34]. Several countries, including the United Kingdom (UK) and Finland, with epidemiologic surveillance and front-of-package "traffic-light" sodium labeling, have successfully carried out salt reduction programs [35,36]. The U.S. may consider these and other strategies in order to impact high sodium intake and its sequelae of health consequences [37].

Our study has several limitations. First, our participants were obese adults (BMI between 30 and 40) with MetS, our sample is also limited, and therefore our findings may not be generalizable to the overall U.S. population. Second, this study measured sodium intake via 24-hour dietary recalls. Self-reported dietary intake may be affected by recall bias and sodium intake is more likely to be underestimated $[4,38]$. Third, the AHA has emphasized that the goal of sodium intake is $1500 \mathrm{mg} / \mathrm{d}$ or less, but few people in our study met this threshold. This study also calculated compliance to the less stringent upper level of $2300 \mathrm{mg} / \mathrm{d}$, which was the prior 2006 AHA 
recommendation $[8,20,23,39]$. Still, few of our participants achieved this goal. While research generally agrees that the lower level of sodium is beneficial to circulatory diseases, the practical reduction of sodium intake may require a step-wise approach to reduce excess sodium intake a realistic and achievable goal for the U.S. population. Finally, since our study was not focused exclusively on reducing sodium, this may contribute to the fact that there was no change in sodium density.

The present study also has several strengths. To our knowledge, this is the first study that reported detailed sodium intake and meal consumption patterns in a dietary intervention trial. In addition, three 24-hour dietary recalls were conducted to collect dietary data at baseline and one-year, which may be more precise than food frequency questionnaires [40].

\section{Conclusions}

This study observed a high percentage of participants who consumed excess sodium even after a dietary intervention directed in part to increase awareness of intake among obese subjects with MetS. Not surprisingly, the sodium intake was higher on weekend days, at lunch and dinner, and when meals were consumed in restaurants and fast food chains. Although the percentage of excess sodium intake decreased after the one-year intervention, sodium reduction was likely accomplished through a decrease in total caloric intake. If the aim of public policy is to reduce sodium intake independently, decreasing the sodium density of commercially prepared food in addition to limiting added salt is necessary. Findings from this study highlight the role of public health policies in helping individuals meet the guidelines and to encourage people to prepare low sodium foods at home.

\section{Competing interests}

The authors declare that they have no competing interests.

\section{Authors' contributions}

JW, BCO, and YM designed the research; BCO, PAM, GFO, and YM carried out the research; JW and YM wrote the draft of initial manuscript; JW, BCO, NMW, GMP, ALC, WL, PAM, JC, HF, ZZ, GFO, LZ and YM critically revised the manuscript for important intellectual content; JW, GFO, and HF analyzed data; PAM and JC provided the essential administrative, technical, or material support. YM and BCO had primary responsibility for final content. All authors read and approved the final manuscript.

\section{Acknowledgements}

The work was supported by grant 5R01HL094575-04 to Dr. Yunsheng Ma from the National Heart, Lung and Blood Institute (NHLBI), and in part by the Pilot Project award to Dr. Hua Fang from, UL1RR031982, National Center for Research Resources.

\section{Author details}

'Department of Preventive Medicine, Medical School of Yangzhou University, Yangzhou, Jiangsu, China. ${ }^{2}$ Division of Preventive and Behavioral Medicine, Department of Medicine, University of Massachusetts Medical School, Worcester, MA, USA. ${ }^{3}$ Division of Biostatistics and Health Services Research, Department of Quantitative Health Science, Clinical and Population Health Research Doctoral Program, University of Massachusetts Medical School,
Worcester, MA, USA. ${ }^{4}$ Division of Biostatistics and Health Services Research, Department of Quantitative Health Science, University of Massachusetts Medical School, Worcester, MA, USA. ${ }^{5}$ Tongji University Medical School, Shanghai, China.

Received: 2 July 2013 Accepted: 9 December 2013 Published: 18 December 2013

\section{References}

1. Mottillo S, Filion KB, Genest J, Joseph L, Pilote L, Poirier P, Rinfret S, Schiffrin EL, Eisenberg MJ: The metabolic syndrome and cardiovascular risk a systematic review and meta-analysis. J Am Coll Cardiol 2010, 56:1113-1132.

2. Appel LJ, Frohlich ED, Hall JE, Pearson TA, Sacco RL, Seals DR, Sacks FM, Smith SC Jr, Vafiadis DK, Van Horn LV: The importance of population-wide sodium reduction as a means to prevent cardiovascular disease and stroke: a call to action from the American Heart Association. Circulation 2011, 123:1138-1143.

3. Bibbins-Domingo K, Chertow GM, Coxson PG, Moran A, Lightwood JM, Pletcher MJ, Goldman L: Projected effect of dietary salt reductions on future cardiovascular disease. N Engl J Med 2010, 362:590-599.

4. Whelton PK, Appel L, Sacco RL, Anderson CA, Antman EM, Campbell N, Dunbar SB, Frohlich ED, Hall JE, Jessup M, et al: Sodium, blood pressure, and cardiovascular disease: further evidence supporting the american heart association sodium reduction recommendations. Circulation 2012, 126:2880-2889.

5. Aburto NJ, Ziolkovska A, Hooper L, Elliott P, Cappuccio FP, Meerpohl JJ: Effect of lower sodium intake on health: systematic review and meta-analyses. BMJ 2013, 346:f1326.

6. Strazzullo P, D'Elia L, Kandala NB, Cappuccio FP: Salt intake, stroke, and cardiovascular disease: meta-analysis of prospective studies. BMJ 2009, 339:b4567.

7. Palar K, Sturm R: Potential societal savings from reduced sodium consumption in the U.S. adult population. Am J Health Promot 2009, 24:49-57.

8. United States, Department of Health and Human Services, United States, Department of Agriculture, United States. Dietary Guidelines Advisory Committee: Dietary quidelines for Americans, 2010. 7th edn. Washington, D.C: G.P.O; 2010.

9. Centers for Disease Control and Prevention (CDC): Vital signs: food categories contributing the most to sodium consumption - United States, 2007-2008. MMWR Morb Mortal Wkly Rep 2012, 61:92-98.

10. Eddy DM, Schlessinger L, Heikes K: The metabolic syndrome and cardiovascular risk: implications for clinical practice. Int J Obes (Lond) 2008, 32(Suppl 2):S5-S10.

11. Mozumdar A, Liguori G: Persistent increase of prevalence of metabolic syndrome among U.S. adults: NHANES III to NHANES 1999-2006. Diabetes Care 2011, 34:216-219.

12. Ford ES, Li C, Zhao G: Prevalence and correlates of metabolic syndrome based on a harmonious definition among adults in the US. J Diabetes 2010, 2:180-193.

13. Ervin RB: Prevalence of metabolic syndrome among adults 20 years of age and over, by sex, age, race and ethnicity, and body mass index: United States, 2003-2006. Natl Health Stat Report 2009, 13:1-7.

14. Rodrigues SL, Baldo MP, de Sa Cunha R, Andreao RV, Del Carmen Bisi Molina M, Goncalves CP, Dantas EM, Mill JG: Salt excretion in normotensive individuals with metabolic syndrome: a population-based study. Hypertens Res 2009, 32:906-910.

15. Chen J, Gu D, Huang J, Rao DC, Jaquish CE, Hixson JE, Chen CS, Chen J, Lu F, Hu D, et al: Metabolic syndrome and salt sensitivity of blood pressure in non-diabetic people in China: a dietary intervention study. Lancet 2009, 373:829-835.

16. Sarno F, Jaime PC, Ferreira SR, Monteiro CA: Sodium intake and metabolic syndrome: a systematic review. Arq Bras Endocrinol Metabol 2009, 53:608-616.

17. Raisanen JP, Silaste ML, Kesaniemi YA, Ukkola O: Increased daily sodium intake is an independent dietary indicator of the metabolic syndrome in middle-aged subjects. Ann Med 2012, 44:627-634.

18. Merriam PA, Ma Y, Olendzki BC, Schneider KL, Li W, Ockene IS, Pagoto SL: Design and methods for testing a simple dietary message to improve weight loss and dietary quality. BMC Med Res Methodol 2009, 9:87.

19. Grundy SM, Cleeman JI, Daniels SR, Donato KA, Eckel RH, Franklin BA, Gordon DJ, Krauss RM, Savage PJ, Smith SC Jr, et al: Diagnosis and 
management of the metabolic syndrome: an American Heart Association/National Heart, Lung, and Blood Institute Scientific Statement. Circulation 2005, 112:2735-2752.

20. American Heart Association Nutrition C, Lichtenstein AH, Appel $\sqcup$, Brands M, Carnethon M, Daniels S, Franch HA, Franklin B, Kris-Etherton P, Harris WS, et al: Diet and lifestyle recommendations revision 2006: a scientific statement from the American Heart Association Nutrition Committee. Circulation 2006, 114:82-96.

21. SF S: Maintaining a nutrient database in a changing marketplace: keeping pace with changing food products - A research perspective. J Food Comp and Anal 2001, 14:315-322.

22. Frison L, Pocock SJ: Repeated measures in clinical trials: analysis using mean summary statistics and its implications for design. Stat Med 1992, 11:1685-1704.

23. Lloyd-Jones DM, Hong Y, Labarthe D, Mozaffarian D, Appel L, Van Horn L, Greenlund K, Daniels S, Nichol G, Tomaselli GF, et al: Defining and setting national goals for cardiovascular health promotion and disease reduction: the American Heart Association's strategic Impact Goal through 2020 and beyond. Circulation 2010, 121:586-613.

24. Cogswell ME, Zhang Z, Carriquiry AL, Gunn JP, Kuklina EV, Saydah SH, Yang Q, Moshfegh AJ: Sodium and potassium intakes among US adults: NHANES 2003-2008. Am J Clin Nutr 2012, 96:647-657.

25. Sodium intake among adults - United States 2005-2006. MMWR Morb Mortal Wkly Rep 2010, 59:746-749.

26. Karanja NM, Obarzanek EVA, Lin P-H, McCullough ML, Phillips KM, Swain JF, Champagne CM, Hoben KP: Descriptive characteristics of the dietary patterns used in the dietary approaches to stop hypertension Trial. J Am Diet Assoc 1999, 99:S19-S27.

27. Anderson CA, Appel $\amalg$, Okuda N, Brown IJ, Chan Q, Zhao L, Ueshima H, Kesteloot H, Miura K, Curb JD, et al: Dietary sources of sodium in China, Japan, the United Kingdom, and the United States, women and men aged 40 to 59 years: the INTERMAP study. J Am Diet Assoc 2010, 110:736-745.

28. Loria CM, Obarzanek E, Ernst ND: Choose and prepare foods with less salt: dietary advice for all Americans. J Nutr 2001, 131:536S-551S.

29. Leung C, Koehler HH, Hard MM: Mineral contents of selected pre-prepared food sampled in a hospital food service line. J Am Diet Assoc 1982, 80:530-536.

30. Campbell NR, Johnson JA, Campbell TS: Sodium consumption: an individual's choice? Int J Hypertens 2012, 2012:860954.

31. Bruemmer B, Krieger J, Saelens BE, Chan N: Energy, saturated fat, and sodium were lower in entrees at chain restaurants at 18 months compared with 6 months following the implementation of mandatory menu labeling regulation in King County, Washington. J Acad Nutr Diet 2012, 112:1169-1176.

32. Institute of Medicine (US) Committee on Strategies to Reduce Sodium Intake, Henney JE, Taylor CL, Boon CS: Strategies to Reduce Sodium Intake in the United States. Washington DC: National Academy of Sciences Press; 2010.

33. Song Y, Liu S: Magnesium for cardiovascular health: time for intervention. Am J Clin Nutr 2012, 95:269-270.

34. He FJ, MacGregor GA: Reducing population salt intake worldwide: from evidence to implementation. Prog Cardiovasc Dis 2010, 52:363-382.

35. Appel LJ, Angell SY, Cobb LK, Limper HM, Nelson DE, Samet JM, Brownson RC: Population-wide sodium reduction: the bumpy road from evidence to policy. Ann Epidemiol 2012, 22:417-425.

36. Pietinen $\mathrm{P}$, Valsta LM, Hirvonen T, Sinkko H: Labelling the salt content in foods: a useful tool in reducing sodium intake in Finland. Public Health Nutr 2008, 11:335-340

37. Sacks G, Rayner M, Swinburn B: Impact of front-of-pack 'traffic-light' nutrition labelling on consumer food purchases in the UK. Health Promot Int 2009, 24:344-352

38. Espeland MA, Kumanyika S, Wilson AC, Reboussin DM, Easter L, Self M, Robertson J, Brown WM, McFarlane M: Statistical issues in analyzing 24-hour dietary recall and 24-hour urine collection data for sodium and potassium intakes. Am J Epidemiol 2001, 153:996-1006.
39. Institute of Medicine (U.S.). Panel on Dietary Reference Intakes for Electrolytes and Water: DRI, dietary reference intakes for water, potassium, sodium, chloride, and sulfate. Washington, D.C: National Academies Press; 2005.

40. Hebert JR, Ebbeling CB, Matthews CE, Hurley TG, Ma Y, Druker S, Clemow L: Systematic errors in middle-aged women's estimates of energy intake: comparing three self-report measures to total energy expenditure from doubly labeled water. Ann Epidemiol 2002, 12:577-586.

doi:10.1186/1475-2891-12-163

Cite this article as: Wang et al:: Challenges in sodium intake reduction and meal consumption patterns among participants with metabolic syndrome in a dietary trial. Nutrition Journal 2013 12:163.

\section{Submit your next manuscript to BioMed Central and take full advantage of:}

- Convenient online submission

- Thorough peer review

- No space constraints or color figure charges

- Immediate publication on acceptance

- Inclusion in PubMed, CAS, Scopus and Google Scholar

- Research which is freely available for redistribution

Submit your manuscript at www.biomedcentral.com/submit
C Biomed Central 